\title{
Naloxone attenuates rat's preference for signaled shock
}

\author{
MICHAEL S. FANSELOW \\ University of Washington, Seattle, Washington 98195
}

\begin{abstract}
Rats were confined and given signaled shock on one side of a shuttlebox and unsignaled shock on the other side. Preference tests revealed that rats injected with the opiate antagonist naloxone during training showed no subsequent side preference, whereas saline control rats preferred the signaled side. The second and third experiments showed that this naloxone effect could not be due to state-dependent learning (generalization decrement), interference with exploratory activity, or the drug making the signal aversive. The results suggest that release of endogenous analgesic substances may constitute a central nervous system preparatory response which mediates a preference for signaled shock.
\end{abstract}

Given a choice between two situations, one in which aversive electric shock is reliably preceded by a stimulus and one in which identical aversive events are not signaled, rats typically choose the signaled shock situation (Lockard, 1963). If rats are given controlled exposure to both conditions (signaled and unsignaled shock), and therefore receive an equivalent number, duration and intensity of shock, they spend most of their time in the place where accurate temporal information is given about shock, even if tests are made in the absence of shock and signals (Collier, 1977). The rat behaves as if the signaled shock was less aversive than the unsignaled shock.

It has been suggested that the signal allows the animal to make a preparatory response which modifies the aversiveness of the shock (Biederman \& Furedy, 1970, 1976; Furedy \& Biederman, 1976; Marlin, Berk, \& Miller, 1978; Perkins, 1968; Perkins, Levis, \& Seymann, 1963). Skeletal preparatory responses have been ruled out by the use of fixed electrode preparations that make modification of shock intensity by a peripheral response unlikely (Miller, Daniel, \& Berk, 1974; Miller, Marlin, \& Berk, 1977; Perkins, Seymann, Levis, \& Spencer, 1966). Such findings have led to the formulation of an alternative explanation that stresses the importance of a predictable shock-free period (Badia, Harsh, Coker, \& Abbott, 1976). According to this hypothesis, the signals' absence demarks a shock-free period which is reinforcing to the animal (Arabian \& Desiderato, 1975; Badia \& Culbertson, 1974; Badia, Harsh, \& Coker, 1975). This paper examines another possibil-

Part of this research was presented at the November 1977 meeting of the Psychonomic Society in Washington, D. C. I would like to thank R. C. Bolles and I. Bernstein for their comments. Naloxone for the first experiment was supplied by John Wenger. Naloxone for Experiments 2 and 3 was generously provided by Endo Laboratories. This research was supported by NSF Grant NBS-76-19912 made to Robert C. Bolles. ity, namely that the signaled shock is made less aversive by a preparatory response that is centrally located.

The discovery of several compounds (i.e., endorphins and enkephalins), endogenous to the brain, which have properties similar to the narcotic analgesics (Hughes, 1975; Hughes, Smith, Kosterlitz, Fothergill, Morgan, \& Morris, 1975) indicate that mammals have a central mechanism capable of modifying the aversiveness of painful events. Exogenously produced endorphins and enkephalins have been shown to have a pharmacological analgesic effect when administered to rats and mice (Belluzzi, Grant, Garsky, Sarantakis, Wise, \& Stein, 1976; Loh, Tseng, Wei, \& Li, 1976; Malick \& Goldstein, 1977). However, it has yet to be demonstrated unequivocally that endogenously produced endorphins and enkephalins have a physiological role in the mediation of pain (Goldstein, Pryor, Otis, \& Larsen, 1976).

If the physiological function of these substances is to reduce the intensity of pain, they should be released in response to painful stimuli. Conditioned release of the endogenous analgesics might then occur to stimuli that predict shock, just as Pavlov's dogs salivated to stimuli that predicted food. Such a Pavlovian mechanism is suggested by Siegel's $(1976,1977)$ evidence that opiate systems are susceptible to Pavlovian conditioning. Therefore, conditioned release of an endogenous analgesic could constitute a central preparatory response, explaining the preference-for-signaledshock phenomenon.

Support for such a mechanism would be provided if prevention of the preparatory response (or a reduction in its effectiveness) attenuated the preference for signaled shock. Naloxone is a specific antagonist (Lewis, Bentley, \& Cowan, 1971) of both endogenous and exogenous analgesics (Belluzzi et al., 1976; Loh et al., 1976; Malick \& Goldstein, 1977; Pert \& Snyder, 1973) as well as acupuncture-induced analgesia 
(Mayer, Price, \& Rafii, 1977). Should naloxone attenuate rats' preference for signaled shock, it would suggest that endogenous analgesics do mediate this phenomenon. The following experiment used a preference-for-signaled-shock paradigm, similar to that of Collier (1977), to test this hypothesis.

\section{EXPERIMENT 1}

\section{Method}

Thirty-two adult male Wistar rats were given a 20 -min habituation session, allowing each to explore a two-compartment shuttlebox. The animals could move freely between compartments, and no shocks or signals were presented at this time. The compartments were made discriminable by painting one with $2.5 \mathrm{~cm}$-wide black and white stripes and the other with similar stripes only $1 \mathrm{~cm}$ wide. The grid floor of the shuttlebox was balanced on a fulcrum. A microswitch registered the floor tilt caused by the rat's weight allowing the rat's position to be monitored.

Following habituation, the animals were divided into four groups and given 4 days of conditioning. Animals in two of the groups received an IP injection of $8 \mathrm{mg} / \mathrm{kg}$ naloxone hydrochloride in an isotonic saline vehicle. The other two groups served as drug controls and received an equivalent volume of isotonic saline at comparable times.

During conditioning, a partition was placed in the shuttlebox to prevent crossing from one side to another. Each rat was given an appropriate injection and then confined to one compartment, in which it received 5 inescapable and unavoidable shocks of $.75 \mathrm{sec}$ duration. The grids were connected by neon bulbs, and a $310-\mathrm{V}$ potential was applied to grids on opposite ends. The shocks were separated by an average interval of $270 \mathrm{sec}$. After receiving the 5 shocks, the rat was placed on the other side of the box and given an equivalent 5-shock session. Due to the relatively long duration of conditioning $(90 \mathrm{~min})$, the animal was removed from the box and given a supplemental injection that was identical to the first. It was immediately returned to the side from which it was taken for another 5-shock session. It was then placed on the initial side for a final 5-shock session. In summary, each rat received 20 shocks and two injections a day for $\mathbf{4}$ days. One saline and one naloxone group received signaled shock on one side and unsignaled shock on the other. The remaining two groups, one of which received saline and the other naloxone, served as controls for the signaled condition. They received unsignaled shock on both sides of the shuttlebox. The signal was a $20-\mathrm{sec}, 3,000-\mathrm{Hz}, 84-\mathrm{dB}$ tone, which immediately preceded the shock. Whether the signal occurred on the wide or thin striped side was decided at random.

The next day, the rat's side preference was tested. The partition was removed from the shuttlebox and the rat was allowed to move freely between sides for $20 \mathrm{~min}$, as in the habituation session. The rats were placed in the center of the box, and the amount of time spent on each side was recorded. No injections, shocks, tones, or any other stimulus changes occurred.

\section{Results and Discussion}

Figure 1 shows the mean percentage of time the animals spent on the signaled side. For the control animals, which had no signal on either side, the side which had been signaled for a matched experimental animal was arbitrarily designated as the signaled side. An analysis of variance (Edwards, 1972, pp. 184-190) showed that there was a significant Drug by Signal interaction $(F=4.28, \mathrm{df}=1 / 24, \mathrm{p}<.05)$. Pairwise comparisons (Edwards, 1972, pp. 136-141) indicated that the signaled-naloxone group did not differ signif-

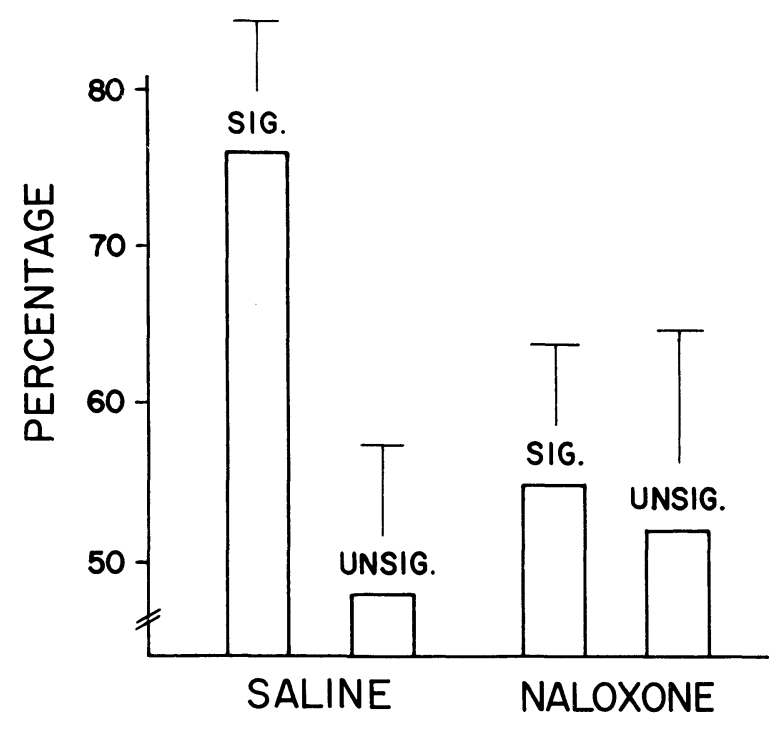

Figure 1. The signaled groups (SIG.) received signaled shock on one side of the shuttlebox and unsignaled shock on the other. The mean $( \pm$ S.E.M.) percentage of the time spent on the signaledshock side of the shuttlebox during the 20 -min test session is displayed. The unsignaled control group (UNSIG.) received shock only on both sides of the shuttlebox. The mean $( \pm$ S.E.M.) percentage of the test session spent on the same side as a matched animal in the experimental group is displayed.

icantly from either the unsignaled-naloxone group or the combined unsignaled controls, while the difference between the signaled-saline and signalednaloxone groups was significant $(p<.05)$. In the signaled-saline group, seven out of eight animals spent more than $50 \%$ of their time on the signaled side, while just four out of eight did so in the signaled naloxone group. Clearly, naloxone attenuated the preference for signaled shock. The main effect for signaled vs. unsignaled shock groups was also significant $(F=6.69$, df $=1 / 24, p<.025)$, while the main effect for drug was not $(F=2.76$, df $=1 / 24$, $\mathrm{p}>.10$ ).

\section{EXPERIMENT 2}

When an animal learns a particular response in the presence of a drug, it often does not demonstrate the response in the absence of the drug (Overton, 1967). The drug state acts as a cue for the response, and removal of this cue causes a deficit in expression of the learned behavior due to this stimulus generalization decrement. Since demonstration of the learned behavior is dependent on the presence of the drug state, it is called state-dependent learning. It may be noted that no drugs were given during the test phase of Experiment 1 . If expression of the preference for signaled shock were dependent on interoceptive stimuli produced by the naloxone, demonstration of the preference in the signaled-naloxone group may have been 
attenuated by generalization decrement (i.e., it was state dependent upon naloxone). State-dependent learning effects have been demonstrated in fear conditioning situations (e.g., Heistad \& Torres, 1959).

The importance of state-dependent learning can be assessed by using a two-factor design, where presence or absence of the drug during training is combined with its presence or absence during testing (Miller, 1957). If performance is superior in the unchanged as compared to the changed groups (i.e., a significant two-factor interaction), state-dependent learning is of importance. The present experiment employed such a two-factor design.

\section{Method}

Thirty-two additional male adult Wistar rats were run in an experiment identical to the first except in two respects. First, all animals received signaled shock on one side and unsignaled on the other. Second, naloxone or saline injections were administered immediately before the preference test in a factorial combination with the type of injection received during training.

\section{Results and Discussion}

In order to correct for the animals' initial side bias, a difference score was calculated by subtracting the percentage of time spent on the signaled side during habituation from the percentage of time spent on the signaled side during testing. These difference scores were subjected to a two-factor analysis of variance. The drug (saline vs. naloxone) during training factor was significant $(F=5.49, \mathrm{df}=1 / 28, \mathrm{p}<.05)$. The animals trained with saline spent $62 \%$ of their time on the signaled side as compared to $43 \%$ for the naloxone trained animals, thereby replicating naloxone's attenuation of the preference for signaled shock found in the first experiment.

Animals tested with naloxone spent $57 \%$ of the test session on the signaled side, while animals tested with saline spent $48 \%$ of their time on the signaled side; this difference is not reliable $(F<1)$. The absence of a drug effect during testing indicates that naloxone did not cause any general interference with the animals' choice behavior or discriminative ability. Most importantly, the interaction of these factors was not reliable $(F<1)$, indicating that state-dependent learning (generalization decrement) was not a significant factor in these results.

\section{EXPERIMENT 3}

If endogenous analgesics are being released at some constant rate, naloxone might make incoming stimulation more aversive. If naloxone made all the shocks more aversive, it should not have affected the side preference, as the rats had the same number of shocks on both sides. Conceivably, one might expect that naloxone would increase the preference, if it increased the shocks' aversiveness, since more intense shocks seem to produce a stronger preference (Harsh \& Badia, 1975).

However, tone was present only on the signaled side. If naloxone increased the aversiveness of the tone, it might have caused an avoidance for the signaled side that tended to cancel the preference for that side. The third experiment looked at this possibility.

\section{Method}

Sixteen naive rats, from the same population as the previous experiments, were allowed to explore the shuttleboxes freely for $10 \mathrm{~min}$. One half of the animals received an $8-\mathrm{mg} / \mathrm{kg}$ injection of naloxone, while the other half received an equivalent volume of saline before being placed in the box. If the animals crossed to the tone side of the box, the same signal used in Experiments 1 and 2 was presented within $.5 \mathrm{sec}$; likewise, on crossing to the silent side of the box, the tone was terminated within $.5 \mathrm{sec}$. Tone or silence was continuous as long as the animal remained on one side of the box. One half of each drug group had the tone on the wide-striped side, and the other half had it on the thin-striped side.

\section{Results and Discussion}

The tone did not affect the rats' exploratory activity, as the animals spent $48 \%$ of the time on the tone side. Naloxone did not appear to make the tone aversive, as naloxone-treated animals spent $50 \%$ of the time on the tone side, while saline-treated animals spent $47 \%$ of the time on the tone side. This difference was not reliable $(t=.58)$. Furthermore, four out of eight naloxone animals were on the tone side at the end of the test session.

The number of times the animals crossed from one side of the shuttlebox to the other was analyzed by a split-plot repeated-measures analysis of variance (Edwards, 1972; pp. 334-340), with successive 2-min blocks of the test period treated as trials. The trial effect was significant $(F=10.56$, df $=4 / 56$, p $<.005$ ), indicating that the animals tended to cross less as time went on (see Figure 2). Naloxone had no effect on the number of crossovers $(F<1.0)$, nor did the drug interact with the number of crossovers over trials $(\mathrm{F}<1.0)$.

This finding indicates that the attenuation of preference for signaled shock demonstrated in Experiments 1 and 2 could not have been caused by an added aversiveness of the signal. Nor could this effect have been accomplished indirectly by some drug effect on locomotor or exploratory behavior, since the number of crossovers was not affected.

\section{GENERAL DISCUSSION}

Naloxone, when given to animals during training, blocked the preference for signaled shock that rats normally show. It is unlikely that naloxone itself interfered with learning or performance. Other researchers have found doses higher than the ones used here not to disrupt performance on a variety of tasks 


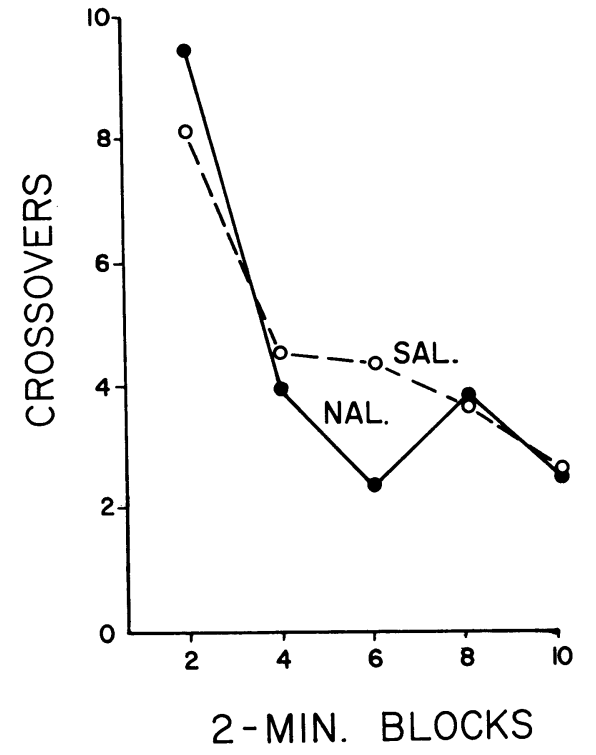

Figure 2. Number of times the rats crossed from one side of the shuttlebox to the other during the 10-min test session.

(escape learning, Goldstein et al., 1976; barpressing for appetitive brain stimulation, Van Der Kooy, LePiane, \& Phillips, 1977; Sidman avoidance, Holtzman \& Jewett, 1973; and locomotor activity, Holtzman \& Jewett, 1973). In the third experiment reported here, naloxone was found to have no effect on exploration in the shuttlebox. In the first experiment, observation of the unsignaled saline and naloxone groups revealed no obvious behavioral differences and within-group variability was similar $(F<1.0)$. In the second experiment, naloxone did not block expression of the preference, if only given on the test day. Finally, some of the animals in the second experiment were tested in another apparatus for conditioned fear to the tone. Substantial suppression of activity was evident in all groups. This seemingly paradoxical finding - that the signal elicits fear, yet is preferredhas been found by other researchers (Collier, 1977; Harsh \& Badia, 1974). In the present context, suppression of activity in response to the tone for the naloxone-trained animals indicates that the drug did not interfere with learning the CS-US association.

These data support the hypothesis that the signal causes conditioned release of an endogenous analgesic that decreases the aversiveness of shock. This analgesic activity must take effect rapidly (within the 20-sec signal-shock interval) and be short-lived (loss of the analgesic effect within the 270-sec intershock interval). If this is indeed the case, the preference phenomenon may provide a useful behavioral assay of the physiological release of endogenous analgesics. Also, the role of endogenous analgesics in other aversive learning situations needs to be explored.

\section{REFERENCES}

Arabian, J. M., \& Desiderato, O. Preference for signaled shock: A test of two hypotheses. Animal Learning \& Behavior, 1975, 3, 191-195.

Badia, P., \& Culbertson, S. Changeover from unsignaled to signaled avoidance with and without a feedback stimulus in rats. Animal Learning \& Behavior, 1974, 2, 278-284.

Badia, P., Harsh, J., \& Coker, C. C. Choosing between fixed time and variable time shock. Learning and Motivation, 1975, 6, 260-278.

Badia, P., Harsh, J., Coker, C. C., \& Aвbott, B. Choice and the dependability of stimuli that predict shock and safety. Journal of the Experimental Analysis of Behavior, 1976, 26, 95-111.

Belluzzi, J. D., Grant, N., Garsky, V., Sarantakis, D., Wise, C. D., \& Stein, L. Analgesia induced in vivo by central administration of enkephalin in rat. Nature, 1976, 260, 625-626.

Biederman, G. B., \& Furedy, J. J. Preference for signaled shock in rats? Instrumentation and methodological errors in the archival literature. Psychological Record, 1976, 26, 501-514.

Biederman, G. B., \& FuREDY, J. J. The preference-for-signalledshock phenomenon: Signalling shock is reinforcing only if shock is modifiable. Quarterly Journal of Experimental Psychology, 1970, 22, 681-685.

Collier, A. C. Preference for shock signals as a function of the temporal accuracy of the signals. Learning \& Motivation, 1977, 8, 159-170.

EDWARDs, A. L. Experimental design in psychological research (4th ed.). New York: Holt, Reinhart \& Winston, 1972.

Furedy, J. J., \& Biederman, G. B. Preference for signaled shock phenomenon: Direct and indirect evidence for modifiability factors in the shuttlebox. Animal Learning \& Behavior, 1976, 4, 1-5.

Goldstein, A., Pryor, G. T., Otis, L. S., \& Larsen, F. On the role of endogenous opiod peptides: Failure of naloxone to influence shock escape threshold in the rat. Life Sciences, 1976, 18, 599-604.

HARSH, J., \& BADIA, P. A concurrent assessment of the positive and negative properties of a signaled shock schedule. Animal Learning and Behavior, 1974, 2, 168-172.

HARSH, J., \& BADIA, P. Choice for signalled over unsignalled shock as a function of shock intensity. Journal of the Experimental Analysis of Behavior, 1975, 23, 349-355.

Heistad, G. T., \& Torres, A. A. A mechanism for the effect of a tranquilizing drug on learned emotional responses. Medical Bulletin, University of Minnesota, 1959, 30, 518-527.

Holtzman, S. G., \& JeweTt, R. E. Stimulation of behavior in the rat by cyclazocine: Effects of naloxone. Journal of Pharmacology and Experimental Therapeutics, 1973, 187, 380-390.

HuGHES, J. Isolation of an endogenous compound from the brain with pharmacological properties similar to morphine. Brain Research, 1975, 88, 295-308.

Hughes, J., Smith, T. W., Kosterlitz, H. W., Fothergill, L. A., Morgan, B. A., \& Morris, H. R. Identification of two related pentapeptides from the brain with potent opiate agonist activity. Nature, 1975, 258, 577-579.

Lewis, J. W., Bentley, K. W., \& Cowan, A. Narcotic analgesics and antagonists. Annual Review of Pharmacology, 1971, 11, 241-270.

LOCKARD, J. S. Choice of a warning signal or no warning signal in an unavoidable shock situation. Journal of Comparative and Physiological Psychology, 1963, 56, 526-530.

LOH, H. H., Tseng, L. F., WEI, E., \& LI, C. H. B. Endorphin is a potent analgesic agent. Proceedings of the National Academy of Science, 1976, 73, 2895-2898.

Malick, J. B., \& Goldstein, J. M. Analgesic activity of enkephalins following intracerebral administration in the rat. Life Sciences, 1977, 20, 827-832. 
Marlin, N. A., Berk, A. M., \& Miller, R. R. Modification and avoidance of unmodifiable and unavoidable footshock. Bulletin of the Psychonomic Society, 1978, 11, 203-205.

MAYer, D. J., PRICE, D. D., \& RAFII, A. Antagonism of acupuncture analgesia in man by the narcotic antagonist naloxone. Brain Research, 1977, 121, 368-372.

MilleR, N. E. Objective techniques for studying motivational effects of drugs. In S. Garattini and V. Ghetti (Eds.), Psychotropic drugs. Amsterdam: Elsevier, 1957.

Miller, R. R., DANiel, D., \& Berk, A. M. Successive reversals of a discriminated preference for signaled tailshock. Animal Learning \& Behavior, 1974, 2, 271-274.

Miller, R. R., Marlin, N. A., \& Berk, A. M. Reliability and sources of control of preference for signaled shock. Animal Learning \& Behavior, 1977, 5, 303-308.

Overton, D. A. Dissociated learning in drug states (state dependent learning). In D. H. Efron, J. O. Cole, J. Levine, \& J. R. Wittenborn (Eds.), Psychopharmacology: A review of progress 1957-1967. Washington: Public Health Service Publication No. 1836, 1968.

Perkins, C. C., JR. An analysis of the concept of reinforcement. Psychological Review, 1968, 75, 155-172.
Perkins, C. C., JR., Levis, D. J., \& Semmann, R. Preference for signal-shock vs. shock-signal. Psychological Report, 1963, 13, 735-738.

Perkins, C. C., Jr., Seymann, R. G., Levis, D. J., \& Spencer, H. R., JR. Factors affecting preferences for signal-shock over shock-signal. Journal of Experimental Psychology, 1966, 72, 190-196.

Pert, C. B., \& SNyder, S. H. Opiate receptor: Demonstration in nervous tissue. Science, 1973, 179, 1011-1014.

SIEGEL, S. Morphine analgesic tolerance: Its situational specificity supports a Pavlovian conditioning model. Science, 1976, 193, 323-325.

SIEGEL, S. Morphine tolerance acquisition as an associative process. Journal of Experimental Psychology: Animal Behavior Processes, 1977, 3, 1-13.

Van Der Kooy, D., LePiane, F. G., \& Phillips, A. G. Apparent independence of opiate reinforcement and electrical selfstimulation systems in rat brain. Life Sciences, 1977, 20, 981-986.

(Received for publication July 25, 1978; revision accepted December 4, 1978.) 